\title{
PRODUÇÃO DE ENZIMAS ACESSÓRIAS RECOMBINANTES PARA SUPLEMENTAÇÃo DE COQUETEL ENZIMÁTICO DE L.THEOBROMAE PARA APLICAÇÃO NA HIDRÓLISE DO BAGAÇO
}

\author{
K. KATAYAMA ${ }^{1}$, A.G. TAVARES ${ }^{1}$, C.B. COSTA $^{1}$, V.M. GONÇALVES ${ }^{2}$, J.G.C. \\ PRADELLA $^{1}$ e S. FREITAS ${ }^{1}$ \\ ${ }^{1}$ Centro Nacional de Pesquisa em Energia e Materiais (CNPEM), Laboratório Nacional de \\ Ciência e Tecnologia do Bioetanol (CTBE) \\ ${ }^{2}$ Instituto Butantan, Centro de Biotecnologia \\ E-mail para contato: karla.yukari@bioetanol.org.br
}

\begin{abstract}
RESUMO - A produção de coquetéis enzimáticos eficientes é imprescindível para a hidrólise de material lignocelulósico visando à obtenção de açúcares fermentescíveis. Uma das abordagens mais promissoras é o enriquecimento de coquetéis fúngicos em termos de atividades que lhes faltam, que podem ser obtidas através de sistemas heterólogos. O objetivo deste trabalho é o desenvolvimento do processo de produção de hidrolases recombinantes em $E$. coli visando à suplementação do coquetel enzimático do fungo $L$. theobromae para aplicação eficiente na sacarificação de bagaço de cana-deaçúcar pré-tratado, uma vez que a caracterização do coquetel secretado por este fungo evidenciam a carência de celulases, em especial da classe endoglucanásica, em sua composição. A plataforma de expressão heteróloga está baseada na linhagem comercial $E$. coli SE1 cujo sistema de estabilização independe de antibiótico, reduzindo custos na produção da enzima, além de facilitar o tratamento dos efluentes. A construção dos clones em SE1 e os ensaios de expressão da endoglucanase demonstram que este sistema de expressão é promissor.
\end{abstract}

\section{INTRODUÇÃO}

A reação da hidrólise enzimática permanece como uma etapa crítica no processo de conversão de biomassa lignocelulósica em etanol, sendo que uma grande variedade de atividades enzimáticas é necessária. As preparações enzimáticas comerciais atualmente disponíveis para a despolimerização de materiais lignocelulósicos são misturas complexas de proteínas isoladas a partir de fungos filamentosos, tais como Trichoderma reesei. As atuais misturas de enzimas comerciais, genericamente nomeadas "celulase", contêm entre 80 e 200 proteínas (Banerjee et al., 2010). No entanto, exceto por algumas das celulases e hemicelulases melhor caracterizadas, conhece-se muito pouco sobre a maioria destas proteínas presentes. 


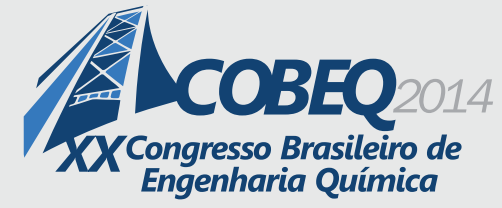

O aumento da eficiência dos coquetéis enzimáticos está relacionado com a expressão balanceada das diferentes atividades necessárias para a desconstrução da parede celular. Muitas destas atividades são produzidas em baixíssimas concentrações por fungos, mesmo aqueles considerados super produtores. Tais proteínas são excelentes candidatas para a expressão heteróloga a fim de se poder suplementar coquetéis fúngicos. Assim, torna-se importante o desenvolvimento de plataformas de expressão heteróloga robustas capazes de produzir enzimas a baixo custo com o mínimo de limitações no que diz respeito à utilização em larga escala.

Dentre os hospedeiros heterólogos utilizados, Escherichia coli destaca-se fortemente na produção de proteínas recombinantes, seja na indústria farmacêutica, veterinária, alimentícia, entre outros. A principal motivação está no fato de este ser um organismo bem caracterizado do ponto de vista genético, fisiológico e de expressão (Choi et al., 2006). Apesar de todas as conhecidas vantagens do uso da $E$. coli como hospedeiro, a instabilidade plasmidial é uma preocupação significativa para a utilização industrial destes OGMs, uma vez que estas construções utilizam vetores bacterianos que contém um gene de resistência a antibiótico como marcador seletivo (Spirer et al., 2005; Peubez et al., 2010). Os antibióticos (ou seus produtos oriundos da degradação) podem contaminar a biomassa ou produto, tornando-se necessária a sua remoção do produto final e efluente (Spirer et al., 2005). Além disto, o uso de antibióticos em condições de cultura intensiva (alta densidade celular e/ou cultivo contínuo) não é eficiente devido à sua diluição ou inativação (Baneyx, 1999). Na questão regulatória, o grau de aceitabilidade está restrito a canamicina e tetraciclina, contudo há uma expectativa de que haja "tolerância zero" em relação aos sistemas de produção e seleção baseados em antibióticos (Sodoyer et al., 2012).

Neste contexto, algumas abordagens têm sido estudadas sendo as mais promissoras a utilização de marcadores auxotróficos baseados na complementação de uma mutação ou deleção no DNA genômico do hospedeiro (Vidal et al., 2008) e a manutenção baseada no sistema "antídoto-toxina" (Szpirer e Milinkovitch, 2005). Nos estudos de Spirer e Milinkovitch (2005), foi demonstrado que após 20 gerações (em meio seletivo ou não), 100\% das bactérias ainda continham o plasmídeo. Duas horas após indução, os plasmídeos ainda estavam presentes em todas as bactérias, o que não é o caso em um sistema padrão pET/BL21(DE3).

O presente trabalho tem como objetivo validar a estratégia de obtenção de um sistema de expressão livre de antibiótico e apresentar os dados de construção e obtenção do clone de $E$. coli SE1 para a expressão de endoglucanase recombinante visando suplementar o coquetel enzimático do coquetel do fungo Lasiodiplodia theobromae MIBA-0016 a fim de torna-lo mais eficiente para a hidrólise de bagaço de cana-de-açúcar pré-tratado. 


\section{MATERIAIS E MÉTODOS}

\subsection{Painel enzimático}

O fungo utilizado neste trabalho foi o Lasiodiplodia theobromae MIBA-0016, isolado do bioma amazônico e cedido pelo Prof. Alberdan Santos da Universidade Federal do Pará. O microorganismo foi mantido em geladeira em PDA e repicado periodicamente para a sua manutenção. Para a caracterização do coquetel enzimático secretado pelo fungo, foi realizado um cultivo de acordo com as condições otimizadas por Costa (2013) e realizado um ensaio enzimático contra diferentes substratos, p-nitrofenol (p-NP) e os derivados de celulose e materiais não celulósicos, com posterior determinação da quantidade de açúcar redutor liberado. As atividades do coquetel enzimático obtidas encontram-se apresentadas na Tabela 1.

Tabela 1 - Valores de atividade enzimática obtidas em ensaio de painel enzimático com coquetel fúngico produzido por Lasiodiplodia theobromae.

\begin{tabular}{lcc}
\hline \multicolumn{1}{c}{ Substrato } & Atividade volumétrica (U/ml) & Atividade específica (U/mg) \\
\hline CMC & 1,149 & 3,407 \\
Larch arabinogalactan & 0,425 & 1,261 \\
Linear arabian & 0,657 & 1,950 \\
Glucomanana & 9,159 & 27,167 \\
Beta-glucana & 2,139 & 6,344 \\
1,4- $\beta$-D-manana & 2,842 & 8,429 \\
Pectina & 0,865 & 2,567 \\
Xilana & 18,918 & 56,118 \\
pNpC & 0,396 & 1,175 \\
pNpG & 0,532 & 1,579 \\
\hline
\end{tabular}

Atividade celulolitica total (Fpase)

\begin{tabular}{ll}
\hline FPU/mL & FPU/mg \\
\hline 0,491 & 1,458 \\
\hline
\end{tabular}

As condições de crescimento do fungo foram em tampão ftalato de sódio, $\mathrm{pH}=5,9$; temperatura de $29^{\circ} \mathrm{C}$, tendo como fonte de carbono principal o bagaço da cana de açúcar pré tratado hidrotermicamente e com $\mathrm{NaOH}$ a 1,5\%. As atividades enzimáticas em substratos hemicelulósicos tais como Glucomanana, $\beta$-glucana, 1,4- $\beta$-D-manana e Xilana apresentam atividades expressivas quando comparadas à atividade total celulolitica $(0,49 \mathrm{FPU} / \mathrm{mL})$ ou mesmo a atividade contra o CMC levando-se a concluir que este coquetel apresenta uma deficiência de atividades relacionadas à hidrólise de celulose e portanto enzimas das classes endoglucanásicas, celobiohidrolásicas, e enzimas auxiliares tais como as expansinas, são as potenciais candidatas à suplementação deste coquetel. 


\subsection{Sistemas de expressão}

O microrganismo utilizado no estudo foi a Escherichia coli BL21 (DE3) (Merck, USA), portando o vetor pET-28a(+) (Novagen), carregando o gene da enzima $\beta-1,3-1,4$-glucanase, uma endoglucanase proveniente de Bacillus subtilis. O vetor em questão possui um gene de resistência à canamicina e a expressão da proteína recombinante é regulada através do Operon lac (Figura 1).

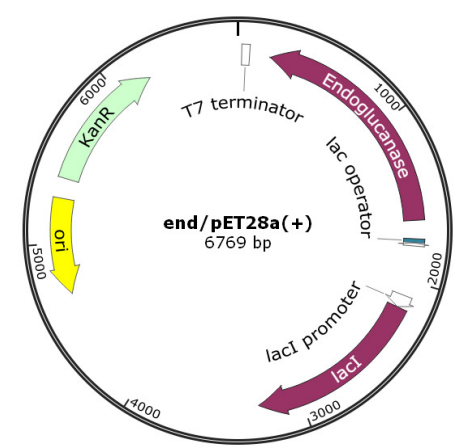

Figura 1 - Mapa do plasmídeo construído em vetor pET-28a(+) com o inserto de $\beta$-1,3-1,4glucanase.

A partir deste sistema de expressão foi realizada a clonagem para possibilitar expressão na linhagem SE1 (Delphi Genetics, Bélgica), a qual possui em seu genoma o gene que codifica a proteína $\operatorname{ccdB}$, um inibidor de DNA girase, letal à bactéria. A ação tóxica do ccdB pode ser evitada pela presença da proteína ccdA, cujo gene deve estar no plasmídeo, formando assim o sistema de estabilização do plasmídeo sem a necessidade do uso de antibióticos. A construção do vetor foi realizada a partir da clonagem do cassete do gene ccdA do plasmídeo pStaby (Figura 2a), fornecido no kit StabyExpress (Delphi Genetics) e adicionando-o ao plasmídeo já construído end/pET-28a(+) (Figura 2b).

a)

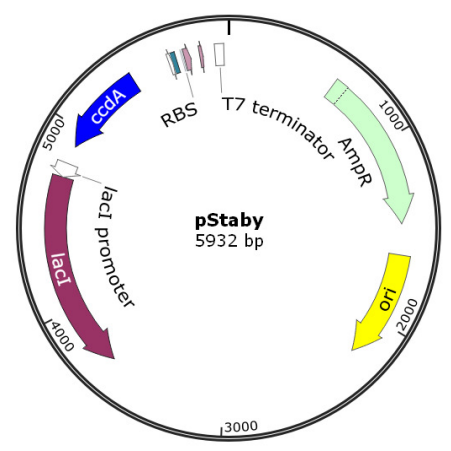

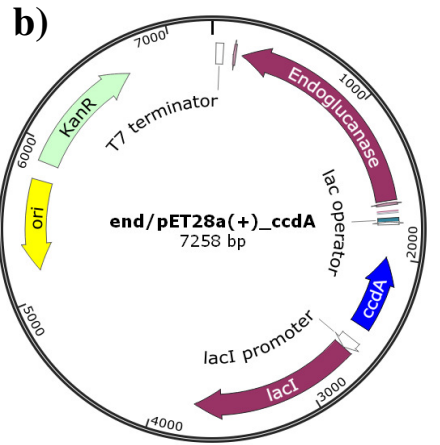

Figura 2 - Mapa do plasmídeo pStaby (a) e do plasmídeo com o inserto de $\beta$-1,3-1,4-glucanase e cassete ccdA em pET-28a(+) (b), evidenciando a localização do cassete subclonado. 
Após a reação de ligação ser realizada, este produto foi utilizado para transformar células SE1 eletrocompetentes. Para confirmar a presença do gene da endoglucanase e do cassete do gene ccdA foram realizadas reações de PCR com primers específicos a eles (Tabela 2).

Tabela 2 - Primers utilizados na reação de PCR para confirmação da presença do gene de interesse da endoglucanase e do cassete ccdA.

\begin{tabular}{ll}
\hline Primer & Sequência \\
\hline ccdAF & 5' - GAGCATGCGTTGTCCACGTTGTCCACGGGCCGAGCG - 3' \\
ccdAR & 5' - CCGCATGCTCACCAGTCCCTGTTCTCG - 3' \\
endFBamHI & 5' - TATATAGGATCCGCAGCAGGGACAAAAACGCC - 3' \\
endRXhoI & 5' - ATATATCTCGAGATTTGGTTCTGTTCCCCAAA - 3' \\
\hline
\end{tabular}

\subsection{Ensaios de expressão da endoglucanase recombinante}

Os experimentos deste trabalho foram realizados em frascos tipo Erlenmeyer de $500 \mathrm{~mL}$, sob agitação de $250 \mathrm{rpm}$ a $37^{\circ}$, em shaker (Innova 44 - New Brunswick Scientific). A partir de 1 colônia positiva transformante das células de expressão, foram preparados inóculos em $20 \mathrm{~mL}$ de meio LB $(0,5 \%$ extrato de levedura, $1 \%$ triptona, $1 \% \mathrm{NaCl})$. Os ensaios de crescimento e expressão foram realizados com os dois sistemas de expressão, BL21/pET28a e SE1/pET28a_ccda, sendo testadas as condições de cultivo na ausência e presença de antibiótico $(30 \mu \mathrm{g} / \mathrm{mL}$ de canamicina) para ambas as linhagens. Amostras foram coletadas no intervalo de $1 \mathrm{~h}$ durante 9 horas de cultivo, acompanhando-se a densidade óptica em espectrofotômetro a 600nm (Thermo Scientific - Evolution 60). Ao atingir a absorbância entre 0,8 e 0,9 as culturas foram induzidas com a adição de $1 \mathrm{mM}$ de Isopropil- $\beta$-d-tiogalactopiranosídeo (IPTG, Sigma-Aldrich).

\subsection{Metodologia analítica}

As amostras coletadas foram centrifugadas a $12.000 \mathrm{~g}$ por 5 minutos a $4^{\circ} \mathrm{C}$ e o pellet resultante foi ressuspendido em tampão de lise $(25 \mathrm{mM}$ Tris- $\mathrm{HCl} \mathrm{pH} 7,5,150 \mathrm{mM} \mathrm{NaCl}$, $0,3 \mathrm{mg} / \mathrm{mL}$ lisozima, e $1 \mathrm{mM}$ PMSF), seguido de sonicação (Sonics - Vibra Cell). As amostras foram novamente centrifugadas, sendo o sobrenadante recuperado para determinação de atividade enzimática e concentração de proteínas totais.

A concentração de proteínas totais foi determinada pelo método de Bradford (Bradford, 1976), utilizando o reagente Bio-Rad Protein Assay Dye Reagent (Biorad), seguindo as instruções do fabricante. Para a curva de calibração, foi utilizado albumina de soro bovino (BSA), de 0,05$0,5 \mathrm{mg} / \mathrm{mL}$. A expressão da proteína foi analisada qualitativamente através de eletroforese em gel de policarilamida (SDS-PAGE) a 12\% (Laemmli, 1970), a $120 \mathrm{~V}$ por cerca de $1 \mathrm{~h} 20$. Após a corrida, os géis foram revelados com Azul Brilhante de Coomassie R-250. As amostras foram ajustadas para aplicação correspondente à quantidade de $3 \mu \mathrm{g}$ de proteínas totais. 
A atividade enzimática foi determinada segundo protocolo de Ghose (1987), usando Carboxi-metil-celulose $0,5 \%$ como substrato. $40 \mu \mathrm{L}$ de tampão acetato foram distribuídos em microplacas de 96 poços e $10 \mu \mathrm{L}$ da amostra foram adicionados, seguido de $50 \mu \mathrm{L}$ do substrato. Após a reação ser incubada a $50^{\circ} \mathrm{C}$ por 30 minutos em termociclador (Eppendorf, USA), a quantidade de açúcares redutores foi determinada pelo método do DNA (ácido 3,5-dinitrosalicílico) (Miller, 1959). A curva de calibração foi construída com concentrações de 0,5-5 mM de glucose. A unidade de atividade enzimática foi definida como sendo a quantidade de enzima que libera $1 \mathrm{mmol}$ de glucose por minuto, sendo que as atividades específicas foram determinadas como unidades por mg de proteína.

\section{RESULTADOS E DISCUSSÃO}

\subsection{Obtenção do sistema de expressão em SE1}

Com a obtenção de colônias transformantes, foi realizada reação de PCR com o plasmídeo extraído para confirmar a presença do inserto de endoglucanase usando os pares de primers endFBamHI e endRXhoI, utilizando como controle positivo a construção em pET28a(+) em que sabia-se previamente da presença do gene $(1432 \mathrm{pb})$. Foi realizada também a reação com os pares ccdAF e ccdAR para confirmar a presença do cassete ccdA $(484 \mathrm{pb})$. Foi utilizado como controle positivo o plasmídeo pStaby, de onde foi subclonado tal cassete. A eletroforese em gel de agarose $1 \%$ revelou a confirmação da clonagem, indicando bandas nas alturas desejadas (1500 e 500 pb), as mesmas dos controles positivos (Figura 3).

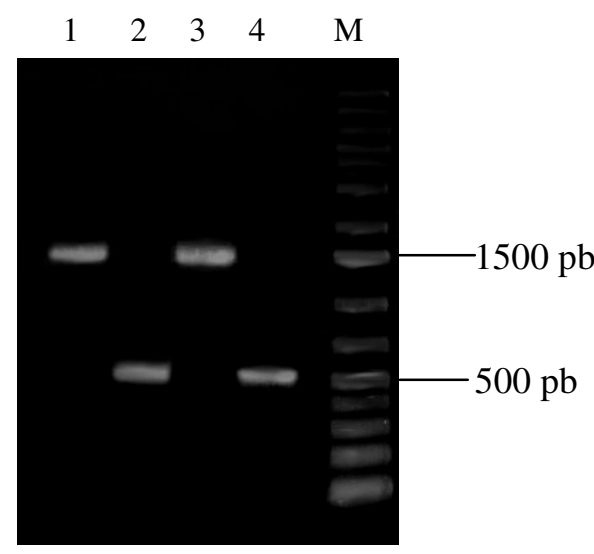

1: clone c/ primers endFBamHI e endRXhoI

2: clone c/ primers ccdAF e ccdAR

3: end/pET28a $(+) \mathrm{c} /$ primers endFBamHI e endRXhoI

4: pStaby c/ primers ccdAF e ccdAR

M: GeneRuler 1kb Plus DNA Ladder

(ThermoScientific)

Figura 3 - Gel de agarose 1\% com produtos da PCR para confirmação da clonagem. 
A estratégia de construção do sistema de expressão em SE1 está definida e a obtenção dos próximos clones para as demais enzimas será facilitada, seguindo o protocolo estabelecido na clonagem do plasmídeo end/pET28a_ccdA.

\subsection{Ensaios de expressão da Endoglucanase}

Foi realizada avaliação de expressão e estabilização plasmidial em estudos em frascos agitados para a produção da proteína recombinante $\beta$-1,3-1,4-glucanase em linhagem de E.coli com sistema independente de antibiótico, comparando-se com a linhagem BL21(DE3). A construção da curva de crescimento das linhagens, como pode ser visualizada na Figura 4, indicou que o crescimento não foi afetado na presença do antibiótico nestas condições de cultivo. As linhagens BL21 e SE1 apresentaram velocidades específicas de crescimento $\left(\mu_{\max }\right)$ semelhantes, sendo a BL21 levemente maior $\left(0,96 \mathrm{~h}^{-1}\right)$ comparado à linhagem SE1 $\left(0,94 \mathrm{~h}^{-1}\right)$.

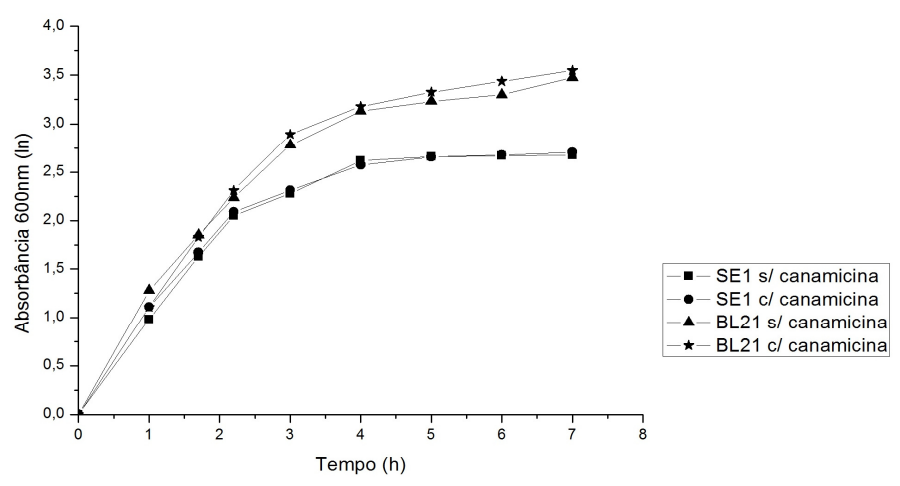

Figura 4 - Curva de crescimento das linhagens BL21 e SE1 para produção de $\beta$-1,3-1,4glucanase, na presença e ausência de sulfato de canamicina $(30 \mu \mathrm{g} / \mathrm{mL})$.

Resultados anteriormente apresentados pelo grupo indicaram que o tempo de $3 \mathrm{~h}$ de indução era o suficiente para atingir os maiores valores para a atividade específica (Silva et al.,2013). Comparando-se os dados de crescimento microbiano e de expressão nas amostras retiradas após $3 \mathrm{~h}$ de indução (Tabela 3), nota-se que a presença de canamicina não afetou a expressão da proteína recombinante tendo-se obtido praticamente a mesma concentração de proteína total e de atividade específica em cultivos com e sem canamicina. Por outro lado, a ausência de canamicina resultou na redução da expressão da proteína recombinante evidenciado pela queda na atividade específica em cerca de $33 \%$. Observa-se que houve um aumento na concentração da proteína total expressa no cultivo de BL21 em meio sem antibiótico, o que pode estar relacionado com a expressão de proteínas relacionadas ao stresse metabólico pela tentativa de sobrevivência do microorganismo neste meio. Por fim, o plasmídeo foi mantido ao longo de $5 \mathrm{~h}$ de cultivo, o que representou uma sobrecarga, contudo este comportamento não é esperado em cultivos de alta densidade celular. 
Tabela 3 - Parâmetros cinéticos das linhagens BL21(DE3) e SE1 na ausência e presença de antibiótico após 3 horas de indução para produção de endoglucanase.

\begin{tabular}{lcccc}
\hline Parâmetro & $\begin{array}{c}\text { BL21 } \\
\text { s/ canamicina }\end{array}$ & $\begin{array}{c}\text { BL21 } \\
\text { c/ canamicina }\end{array}$ & $\begin{array}{c}\text { SE1 } \\
\text { s/ canamicina }\end{array}$ & $\begin{array}{c}\text { SE1 } \\
\text { c/ canamicina }\end{array}$ \\
\hline$\mu_{\text {máx }}\left(\mathrm{h}^{-1}\right)$ & 0,9451 & 0,9754 & 0,9351 & 0,9463 \\
Densidade óptica (600nm) & 3,3100 & 3,3950 & 3,400 & 3,5250 \\
Proteína total $(\mathrm{g} / \mathrm{L})$ & 4,4063 & 2,8848 & 3,1034 & 3,4483 \\
Atividade volumétrica (U/mL) & 2,3972 & 2,3248 & 4,9802 & 5,8968 \\
Atividade específica (U/mg proteína) & 0,5440 & 0,8059 & 1,6047 & 1,7101 \\
\hline
\end{tabular}

A eletroforese em gel de poliacrilamida (SDS-PAGE) indicou que a proteína expressa em SE1 durante o cultivo apresentou o tamanho esperado (cerca de 53kDa) (Figura 5), comparando com a expressão em BL21.

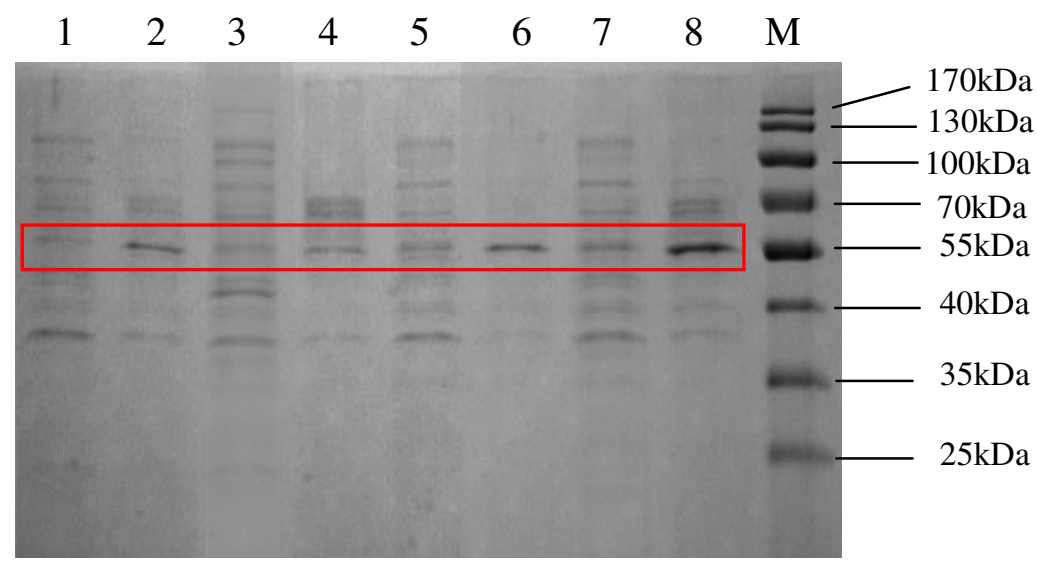

1 e 3: lisado de BL21 antes da indução, sem antibiótico e com antibiótico respectivamente; 2 e 4: após 3h de indução, sem antibiótico e com antibiótico respectivamente;

5 e 7: Lisado de SE1 antes da indução, sem antibiótico e com antibiótico respectivamente; 6 e 8: Lisado de SE1 após 3 h de indução, sem antibiótico e com antibiótico respectivamente. M: marcador de peso molecular.

Figura 5 - Eletroforese em gel de poliacrilamida (SDS-PAGE) das amostras de cultivo com BL21(DE3) e SE1.

\section{CONCLUSÕES}

Os parâmetros cinéticos obtidos neste ensaio em frasco agitado indicaram que a velocidade específica de crescimento das linhagens SE1 e BL21(DE3) foram semelhantes, ou seja, o sistema de estabilidade do plasmídeo utilizando a estratégia de antídoto-toxina é tão eficiente quanto o antibiótico, já conhecido e utilizado, além de não evidenciar nenhuma sobrecarga metabólica à célula.

Visto os resultados promissores obtidos com os ensaios com a endoglucanase, a próxima enzima a ser clonada será a expansina, a qual poderá contribuir para o coquetel do fungo Lasiodiplodia theobromae. Além disso, serão validados protocolos para a clonagem de enzimas com diferentes características, uma vez que o objetivo final é usar este sistema de expressão como plataforma para a produção de misturas em co-cultura. Este conhecimento será importante para viabilizar a obtenção de misturas customizadas para os diferentes bagaços pré-tratados. 


\section{REFERÊNCIAS BIBLIOGRÁFICAS}

BANERJEE, G.; CAR, S.; SCOTT-CRAIG, J.S.; BORRUSCH, M.S.; BONGERS, M.; WALTON, J.D. Synthetic multi-component enzyme mixtures for deconstruction of lignocellulosic biomass. Biores. Tec., v. 101, p. 9097-9105, 2010.

BANEYX, F. Recombinant protein expression in Escherichia coli. Curr. Opin. Biotechnol., v. 10, p. 411-421, 1999.

BRADFORD, M.M. A rapid and sensitive method for the quantitation of microgram quantities of protein utilizing the principle of protein-dye binding. Anal. Biochem., v. 72, p. 248-254, 1976.

CHOI, J.H.; KEUM, K.C.; LEE, S.Y. Production of recombinant proteins by high cell density culture of Escherichia coli. Chem. Eng. Sci., v. 61, p. 876-885, 2006.

COSTA, C.B. Avaliação do potencial de produção de enzimas celulolíticas pelo fungo Lasiodiplodia theobromae MIBA-0016 por fermentação submersa. Relatório de Estágio realizado junto ao Prog. Ind. do CTBE, Campinas, 2013.

GHOSE, T.K. Measurement of cellulase activities. Pure Appl. Chem., v. 59, 257-268, 1987.

LAEMMLI, U.K. Cleavage of structural proteins during the assembly of the head of bacteriophage T4. Nature, v. 2273, p. 397-407, 1970.

MILLER, G.L. Use of dinitrosalicylic acid reagent for determination of reducing sugar. Anal. Chem., v. 31, 426-428, 1959.

PEUBEZ, I.; CHAUDET, N.; MIGNON, C.; HILD, G.; HUSSON, S.; COURTOIS, V.; DE LUCA, K.; SPECK, D.; SODOYER, R. Antibiotic-free selection in E. coli: new considerations for optimal design and improved production. Microb Cell Fact., v.7, p.65, 2010.

SODOYER, R.; COURTOIS, V.; PEUBEZ, I.; MIGNON, C. Antibiotic-Free Selection for BioProduction: Moving Towards a New "Gold Standard“,Antibiotic Resistant Bacteria - A Continuous Challenge in the New Millennium, Dr. Marina Pana (Ed.), ISBN: 978-953-510472-8, InTech, 2012.

SZPIRER, C.Y.; MILINKOVITCH, M.C. Separate-component-stabilization system for protein and DNA production without the use of antibiotics. Biotechniques, v. 38, p. 775-8, 2005.

VIDAL, L.; PINSACH, J.; STRIEDNER, G.; CAMINAL, G.; FERRER, P. Development of na antibiotic-free plasmid selection system based on glycine auxotrophy for recombinant protein overproduction in Escherichia coli. J. Biotechnol., v. 1s34, p. 127-136, 2008. 